Check for updates

Cite this: RSC Adv., 2017, 7, 52048

\section{Synthesis of polyethylene/exfoliated $\mathrm{MoS}_{2}$ nanocomposites by in situ exfoliation polymerization using Ziegler-Natta catalyst intercalated $\mathrm{MoS}_{2} \dagger$}

\begin{abstract}
Hao Zhang, ${ }^{a}$ He-Xin Zhang (DD *bc and Keun-Byoung Yoon*c
A new synthetic route for polyethylene (PE)/exfoliated $\mathrm{MoS}_{2}\left(\mathrm{EMOS}_{2}\right)$ nanocomposites using novel ZieglerNatta catalyst intercalated $\mathrm{MoS}_{2}$ was designed. The catalyst was synthesized by the intercalation of $\mathrm{MoS}_{2}$ with a Grignard reagent, followed by anchoring of $\mathrm{TiCl}_{4}$ into the $\mathrm{MoS}_{2}$ galleries. The intercalated $\mathrm{MoS}_{2}$ was exfoliated to form $\mathrm{PE} / \mathrm{EMOS}_{2}$ nanocomposites during in situ ethylene polymerization. The resultant $\mathrm{PE} / \mathrm{EMOS}_{2}$ nanocomposites had a layered morphology, and they were well dispersed in the PE matrix. In addition, the thermal stability and mechanical properties of PE were significantly enhanced with the introduction of $\mathrm{EMOS}_{2}$. Thus, this work provides a facile approach to the production of PE/EMoS 2 nanocomposites.
\end{abstract}

Received 1st October 2017

Accepted 4th November 2017

DOI: 10.1039/c7ra10853b

rsc.li/rsc-advances

\section{Introduction}

Polyolefins are the most widely used materials, because of their excellent combination of chemical and physical properties, along with low production cost, superior processability and good recyclability. However, for advanced applications, it is necessary to improve the performance of polyolefins, such as stiffness and rigidity. Over the past decades, the study of polyolefin nanocomposites has attracted considerable attention, because of their high potential as materials with improved properties, such as mechanical and thermal stability, flame resistance, and thermal and electrical conductivities.

Two-dimensional (2D) nanomaterials, including graphite, graphene, and inorganic graphene analogs, have been drawing tremendous attention for many potential applications due to the fascinating properties associated with their ultrathin layer structures. ${ }^{1-4}$ Among the layered nanomaterials, molybdenum disulfide $\left(\mathrm{MoS}_{2}\right)$ is one of the most attractive; it has a structure similar to that of graphite..$^{5-9}$ It has been reported that a monolayer of $\mathrm{MoS}_{2}$ has extraordinarily high breaking strength ( $\sim 23$ GPa) and Young's modulus ( $2300 \mathrm{GPa}$ ), which are higher than those of chemically reduced graphene. ${ }^{10,11}$ The aforementioned

${ }^{a}$ College of Food Science and Engineering, National Engineering Lab. for Wheat and Corn Deep Processing, Jilin Agricultural University, Changchun, China

${ }^{b}$ School of Chemistry and Chemical Engineering, Anhui University of Technology, China.E-mail:polyhx@ciac.ac.cn

${ }^{c}$ Department of Polymer Science and Engineering, Kyungpook National University, Korea.E-mail: kbyoon@knu.ac.kr

$\dagger$ Electronic supplementary information (ESI) available. See DOI: 10.1039/c7ra10853b fascinating properties make $\mathrm{MoS}_{2}$ an attractive substitute in the fabrication of high-performance organic-inorganic polymer nanocomposites. For example, $\mathrm{Hu}$ et al. reported a solution blending method to prepare $\mathrm{EMoS}_{2}$-based nanocomposites of polymethyl methacrylate, polystyrene, and polyvinyl alcohol. ${ }^{12-14}$ The resultant polymer/EMoS 2 nanocomposites exhibited enhanced mechanical properties, thermal stability, and fire resistance properties. The uniform dispersion of $\mathrm{EMoS}_{2}$ in the polymer matrix can be achieved by solution mixing, which is the ideal strategy, wherein these polymers are dissolved in common organic solvents. However, the solution mixing process is difficult and uneconomical in the case of polyolefin, since polyolefin are soluble in limited solvents, such as xylene and trichlorobenzene, at high temperature. In our previous reports, ${ }^{15,16}$ the $\mathrm{PE} / \mathrm{EMoS}_{2}$ nanocomposites were prepared through an in situ polymerization of ethylene using $\mathrm{EMoS}_{2}$ containing Ziegler-Natta catalyst. The resulted nanocomposites exhibited enhanced physical properties than neat PE. However, the catalyst preparation process are very complicate, including use excess amount of $n$-butyl lithium to lithiation of $\mathrm{MoS}_{2}$, the longtime lithiation reaction, violent exfoliation reaction, waste too much water to remove lithium salt and longtime vacuum freeze-dried process, and so on.

Therefore, in this research, we reported a Ziegler-Natta catalyst intercalated $\mathrm{MoS}_{2}$. The catalyst preparation process is very simple, including intercalation of a Grignard reagent into $\mathrm{MoS}_{2}$ galleries and anchoring of $\mathrm{TiCl}_{4}$. During the ethylene polymerization, the intercalated $\mathrm{MoS}_{2}$ layers are in situly exfoliated and dispersed in the polymer matrix (no need additional exfoliation process), producing $\mathrm{PE} / \mathrm{EMoS}_{2}$ nanocomposites directly. 


\section{Experimental}

\section{Materials}

Molybdenum disulfide $\left(\mathrm{MoS}_{2}, \sim 6 \mu \mathrm{m}\right), n$-butylmagnesium chloride (BuMgCl, 2.0 M in THF) triethylaluminum (TEA, 1.0 M in hexane), and titanium tetrachloride $\left(\mathrm{TiCl}_{4},>99 \%\right)$ were purchased from Sigma-Aldrich and used as received. Polymergrade ethylene was provided by Korea Petrochemical Ind. Co. Ltd., Korea. $n$-Hexane was distilled from sodium/benzophenone under $\mathrm{N}_{2}$ prior to use.

\section{Preparation of Ziegler-Natta catalyst intercalated $\mathrm{MoS}_{\mathbf{2}}$}

$1 \mathrm{~g}$ of $\mathrm{MoS}_{2}$ was first placed in the autoclave and $20 \mathrm{~mL}$ of BuMgCl was added. The autoclave was heated at $150{ }^{\circ} \mathrm{C}$ for $12 \mathrm{~h}$ under argon atmosphere. After that, the autoclave was cooled to room temperature and the product was filtered, and washed with anhydrous $n$-hexane. The resulting powder was suspended in $n$-hexane $(200 \mathrm{~mL})$. Then, $\mathrm{TiCl}_{4}(10 \mathrm{~mL})$ was added dropwise to the suspension of $\mathrm{MoS}_{2}-\mathrm{MgCl}$ at $0{ }^{\circ} \mathrm{C}$, after which the temperature was increased to $80{ }^{\circ} \mathrm{C}$ $\left(2{ }^{\circ} \mathrm{C} \min ^{-1}\right)$ and the suspension stirred for $4 \mathrm{~h}$. The mixture was filtered to remove the unreacted $\mathrm{TiCl}_{4}$ and then washed several times with hot $n$-hexane. The obtained powdery catalyst was dried under vacuum at $60{ }^{\circ} \mathrm{C}$ for $3 \mathrm{~h}$. The contents of $\mathrm{MoS}_{2}, \mathrm{Mg}$ and $\mathrm{Ti}$ in the resultant catalyst as determined by inductively coupled plasma-atomic emission spectroscopy (ICP-AES) analysis were: $\mathrm{MoS}_{2}-44.7 \mathrm{wt} \%, \mathrm{Mg}-$ $6.6 \mathrm{wt} \%$ and $\mathrm{Ti}-7.4 \mathrm{wt} \%$. The catalyst was also synthesized without the addition of $\mathrm{MoS}_{2}$ for comparison. For this, a similar procedure was followed to prepare the catalyst without including $\mathrm{MoS}_{2}$. The contents of $\mathrm{Mg}$ and $\mathrm{Ti}$ in the resultant catalyst determined by ICP analysis were: $\mathrm{Mg}$ $2.3 \mathrm{wt} \%$, Ti - $14.1 \mathrm{wt} \%$.

\section{Ethylene polymerization}

Ethylene polymerization was performed in a three-neck glass reactor $(300 \mathrm{~mL})$. The reactor was thrice back-filled with $\mathrm{N}_{2}$ and charged with $100 \mathrm{~mL}$ distilled $n$-hexane. The reaction solution was stirred at $40{ }^{\circ} \mathrm{C}$ under 1 bar of ethylene for $5 \mathrm{~min}$, followed by addition of the TEA cocatalyst. Subsequently, the catalyst was added into the reactor, and polymerization was started under a continuous feed of ethylene ( 1 bar). After $0.5 \mathrm{~h}$ polymerization, $10 \mathrm{~mL} \mathrm{HCl-methanol} \mathrm{solution} \mathrm{(10 \% )} \mathrm{was}$ added to the suspension to terminate to polymerization. The mixture was poured into large quantity of methanol $(500 \mathrm{~mL})$ to precipitate the polymer. The product was collected by filtration, and washed with methanol. Then, the product was dried under vacuum at $60{ }^{\circ} \mathrm{C}$ until a constant weight was achieved.

\section{Characterization}

The contents of $\mathrm{Mg}$ and $\mathrm{Ti}$ in the catalyst were determined using inductively coupled plasma-atomic emission spectroscopy (PerkinElmer, Optima 7300DV). Scanning electron microscopy (SEM) images were recorded using a JEOL JSM-6380LV microscope. The morphologies of the support and the catalyst were studied by an optical microscope (ANA-006, Leitz, Germany) equipped with a charge coupled device-based camera for recording the images. The X-ray diffraction patterns were obtained on a Philips X-Pert PRO MRD diffractometer using $\mathrm{Cu}-\mathrm{K} \alpha$ radiation.

The melting temperature $\left(T_{\mathrm{m}}\right)$ of the obtained polymer was determined using differential scanning calorimetry (DSC; DSC131evo, Setaram) at a heating rate of $10{ }^{\circ} \mathrm{C} \mathrm{min}^{-1}$. The sample was heated to $200{ }^{\circ} \mathrm{C}$ and held in the molten state for $3 \mathrm{~min}$ to eliminate the influence of the thermal history. The polymer melt was cooled to $30{ }^{\circ} \mathrm{C}$ at the rate of $10{ }^{\circ} \mathrm{C} \mathrm{min}{ }^{-1}$. The melting point was determined in the second scan. The analysis of the decomposition temperature was conducted under $\mathrm{N}_{2}$ atmosphere using a thermogravimetric analyzer (TGA; Setaram Labsys evo) from 30 to $800{ }^{\circ} \mathrm{C}$ with a programmed heating rate of $10^{\circ} \mathrm{C} \mathrm{min}^{-1}$. The tensile mechanical properties of the polymers were measured using a universal testing machine (Instron M4465). The sample sizes for the tensile drawing experiments were $5.0 \times 75.0 \times 1.0 \mathrm{~mm}^{3}$. The sample gauge length was $25.0 \mathrm{~mm}$, and the crosshead speed was $50.0 \mathrm{~mm} \mathrm{~min}^{-1}$. The preparation process of Ziegler-Natta catalyst intercalated $\mathrm{MoS}_{2}\left(\mathrm{MoS}_{2}-\mathrm{MgCl} / \mathrm{TiCl}_{4}\right.$ catalyst $)$ and $\mathrm{PE} /$ $\mathrm{EMoS}_{2}$ nanocomposites are illustrated in Scheme 1. In the first step, the Grignard reagent $(\mathrm{BuMgCl})$ was intercalated into the $\mathrm{MoS}_{2}$ galleries and obtained $\mathrm{MoS}_{2}-\mathrm{MgCl}$ support, and then treatment with excess $\mathrm{TiCl}_{4}$ to generate $\mathrm{Mg} / \mathrm{Ti}$ catalyst species between $\mathrm{MoS}_{2}$ layers. During the ethylene polymerization process, the layered $\mathrm{MoS}_{2}$ will in situly exfoliated by the polymerization force arising from the propagation of PE chain.

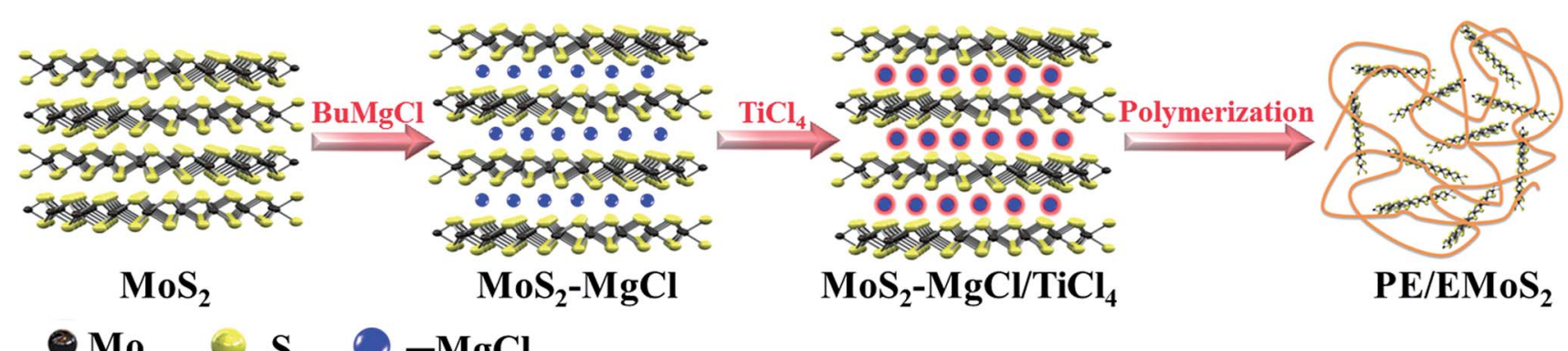

Scheme 1 Preparation of $\mathrm{MoS}_{2}-\mathrm{MgCl}$-supported Ziegler-Natta catalyst and PE/EMoS 2 nanocomposites. 


\section{Results and discussion}

The preparation process of Ziegler-Natta catalyst intercalated $\mathrm{MoS}_{2}\left(\mathrm{MoS}_{2}-\mathrm{MgCl} / \mathrm{TiCl}_{4}\right.$ catalyst $)$ and $\mathrm{PE} / \mathrm{EMoS}_{2}$ nanocomposites are illustrated in Scheme 1. In the first step, the Grignard reagent (BuMgCl) was intercalated into the $\mathrm{MoS}_{2}$ galleries and obtained $\mathrm{MoS}_{2}-\mathrm{MgCl}$ support, and then treatment with excess $\mathrm{TiCl}_{4}$ to generate $\mathrm{Mg} / \mathrm{Ti}$ catalyst species between $\mathrm{MoS}_{2}$ layers. During the ethylene polymerization process, the layered $\mathrm{MoS}_{2}$ will in situly exfoliated by the polymerization force arising from the propagation of PE chain.

The morphologies of the pristine $\mathrm{MoS}_{2}$ sample and the $\mathrm{MoS}_{2}-\mathrm{MgCl} / \mathrm{TiCl}_{4}$ catalyst were studied by SEM analysis. It could be clearly seen from Fig. 1(a), the pristine $\mathrm{MoS}_{2}$ sample contains a large number of tightly stacked $\mathrm{MoS}_{2}$ layers and the diameters are in the range of several micrometers. As shown in Fig. 1(b), after reacted with Grignard reagent and $\mathrm{TiCl}_{4}$, the sheet structure remained and the tightly stacked $\mathrm{MoS}_{2}$ layers cannot be observed on the edge of $\mathrm{MoS}_{2}$. This could be corresponding to the intercalation of Ziegler-Natta catalyst into the $\mathrm{MoS}_{2}$ galleries that blocked the edge of $\mathrm{MoS}_{2}$. The $\mathrm{MoS}_{2}-\mathrm{MgCl} /$ $\mathrm{TiCl}_{4}$ catalyst was also characterized by SEM-EDS (Fig. S1 $\dagger$ ). It was found that the catalyst not only covered the surface of $\mathrm{MoS}_{2}$, but also the galleries of $\mathrm{MoS}_{2}$. Concerning the catalyst in the absence of $\mathrm{MoS}_{2}\left(\mathrm{BuMgCl} / \mathrm{TiCl}_{4}\right)$, the morphology were exhibited as irregular particles.

$\mathrm{XRD}$ analyses were conducted for the pristine $\mathrm{MoS}_{2}, \mathrm{MoS}_{2}-$ $\mathrm{MgCl}-\mathrm{TiCl}_{4}$, and ${\mathrm{BuMgCl}-\mathrm{TiCl}_{4}}_{4}$ catalyst to confirm the successful intercalation of the catalyst into the gallery of $\mathrm{MoS}_{2}$. As shown in Fig. 2, an intense reflection at $2 \theta=14.3^{\circ}$ (the corresponding interlayer distance was $0.62 \mathrm{~nm}$ ) was observed for pristine $\mathrm{MoS}_{2}$, which was attributed to the (002) plane of $\mathrm{MoS}_{2}$. After the treatment with the Grignard reagent and $\mathrm{TiCl}_{4}$, a new peak at $2 \theta=11.2^{\circ}$, which correspond to the layer distances of $0.8 \mathrm{~nm}$, respectively were observed. This clearly indicated that the expansion of the interlayer space is due to the successful intercalation of the Ziegler-Natta catalyst into the $\mathrm{MoS}_{2}$ galleries. Although the reflection at $2 \theta=14.3^{\circ}$ was observed after the intercalation, the peak became very broad and the intensity was drastically reduced compared to that of the pristine $\mathrm{MoS}_{2}$. This phenomenon also proves that $\mathrm{MoS}_{2}$ was successful intercalated by Ziegler-Natta catalyst.

After activation with the TEA cocatalyst, the ethylene polymerization behaviors of the catalysts in the absence and the presence of $\mathrm{MoS}_{2}$ were evaluated. As shown in Table 1, the catalyst activity of $\mathrm{BuMgCl}^{-\mathrm{TiCl}_{4}}$ catalyst were much lower than those with the $\mathrm{MoS}_{2}-\mathrm{MgCl}-\mathrm{TiCl}_{4}$ catalyst. When the equivalent

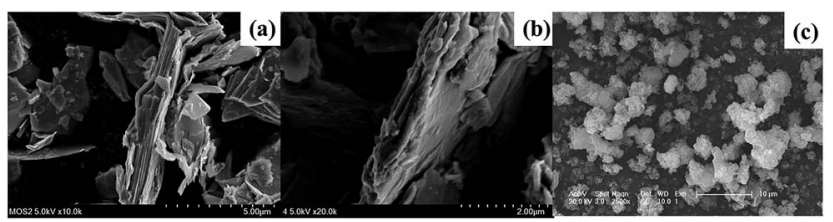

Fig. 1 SEM images of (a) pristine $\mathrm{MoS}_{2}$, (b) $\mathrm{MoS}_{2}-\mathrm{MgCl} / \mathrm{TiCl}_{4}$ catalyst and (c) BuMgCl/TiCl${ }_{4}$ catalyst.

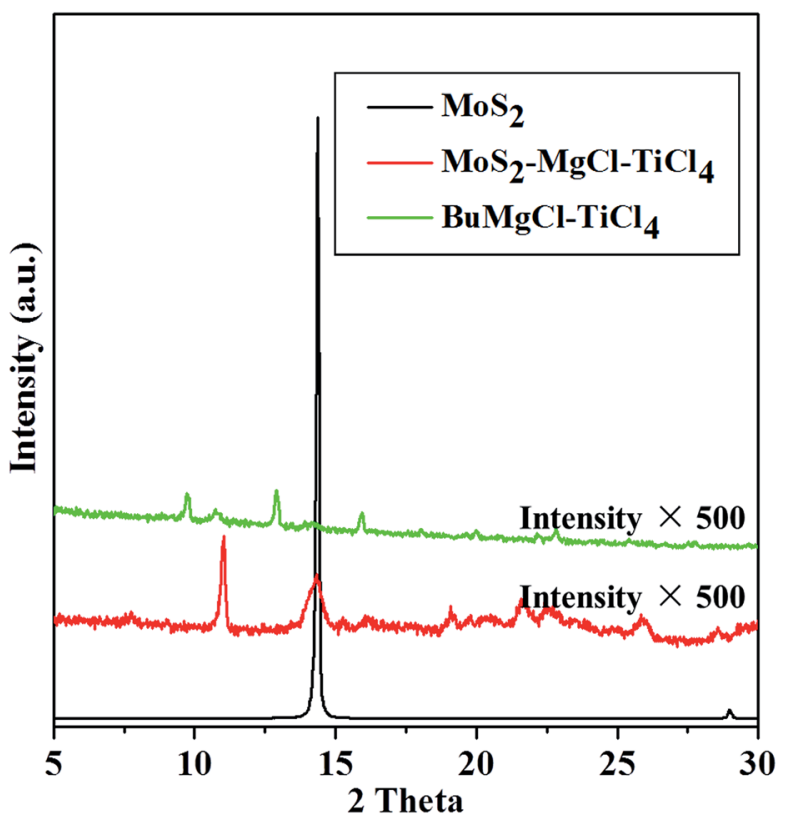

Fig. 2 XRD patterns of pristine $\mathrm{MoS}_{2}, \mathrm{MoS}_{2}-\mathrm{MgCl}-\mathrm{TiCl}_{4}$ and $\mathrm{BuMgCl}-$ $\mathrm{TiCl}_{4}$ catalyst.

weight of catalyst was added (entry $1 v s$. 4), the catalyst activity of $\mathrm{MoS}_{2}-\mathrm{MgCl}-\mathrm{TiCl}_{4}$ is 3.6 times the catalyst in the absence of $\mathrm{MoS}_{2}$. This phenomenon may be due to the fact that $\mathrm{MoS}_{2}$ act as a template to provide a large specific surface area for the Ziegler-Natta catalyst. The $\mathrm{PE} / \mathrm{EMoS}_{2}$ nanocomposites with $\mathrm{EMoS}_{2}$ content of $0.4-3.1 \mathrm{wt} \%$ were obtained in this research by changing the feed weight of the catalyst and $[\mathrm{Al}] /[\mathrm{Ti}]$ ratio.

As shown in Fig. 3, PE obtained using the BuMgCl- $\mathrm{TiCl}_{4}$ catalyst comprised irregularly shaped white particles, while the $\mathrm{PE} / \mathrm{EMoS}_{2}$ nanocomposites showed layered shapes (1-3 $\mathrm{mm}$ ) with homogeneous gray color. This could be ascribed to the morphology of the resultant $\mathrm{PE}$ and the $\mathrm{PE} / \mathrm{EMoS}_{2}$ nanocomposites directly mirror the morphology of the catalyst.

In order to investigate the dispersion of $\mathrm{EMoS}_{2}$, the resultant $\mathrm{PE}$ and $\mathrm{PE} / \mathrm{EMoS}_{2}$ nanocomposites were hot-pressed into films. The polymer films were characterized by optical microscope in the transparent mode; the micrographs are presented in Fig. 4. It was found that the $\mathrm{EMoS}_{2}$ fillers were well dispersed in the PE matrix.

The dispersion of $\mathrm{EMoS}_{2}$ in the $\mathrm{PE} / \mathrm{EMoS}_{2}$ nanocomposites was further confirmed by XRD analyses and the data are presented in Fig. 5. The XRD data of PE/EMoS 2 nanocomposites showed the presence of two diffraction peaks at $21.4^{\circ}$ and $23.8^{\circ}$, which correspond to the (110) and (200) planes of PE (Fig. 5). The peak due to intercalation $\left(11.2^{\circ}\right)$ disappeared completely for $\mathrm{PE} / \mathrm{EMoS}_{2}$ nanocomposites. The disappearance of these peaks is ascribed to the complete exfoliation of the intercalated $\mathrm{EMoS}_{2}$ by the chain propagation force of propylene polymerization. No conspicuous diffraction peaks were observed in addition to the ones of crystalline $\mathrm{PE}$, indicating that no obvious stacking of $\mathrm{EMoS}_{2}$ sheets occurs in the $\mathrm{PE} / \mathrm{EMoS}_{2}$ nanocomposites and that the stacked $\mathrm{MoS}_{2}$ sheets of the catalyst are completely exfoliated. 
Table 1 Results of ethylene polymerization by $\mathrm{MgCl}_{2} / \mathrm{TiCl}_{4}$ and $\mathrm{ODA}-\mathrm{MoS}_{2} / \mathrm{MgCl}_{2} / \mathrm{TiCl}_{4}$ catalysts ${ }^{a}$

\begin{tabular}{|c|c|c|c|c|c|c|c|c|}
\hline Entry & Cat. & Cat. (mg) & {$[\mathrm{Al}] /[\mathrm{Ti}]$} & Activity $\left(\mathrm{kg} \mathrm{mol} \mathrm{Ti}^{-1} \mathrm{~h}^{-1}\right)$ & ODA-MoS $2(w t \%)$ & $T_{\mathrm{m}}\left({ }^{\circ} \mathrm{C}\right)$ & $T_{\mathrm{c}}\left({ }^{\circ} \mathrm{C}\right)$ & $X_{\mathrm{c}}(\%)$ \\
\hline 1 & $\mathrm{BuMgCl} / \mathrm{TiCl}_{4}$ & 100 & 50 & 17.3 & - & 133.2 & 116.2 & 52.5 \\
\hline 2 & $\mathrm{MoS}_{2}-\mathrm{MgCl}-\mathrm{TiCl}_{4}$ & 25 & 200 & 129.7 & 0.4 & 136.0 & 118.0 & 60.9 \\
\hline 4 & & 100 & 50 & 62.3 & 0.9 & 135.4 & 118.3 & 68.9 \\
\hline 5 & & 200 & 25 & 29.8 & 2.0 & 135.5 & 118.6 & 71.9 \\
\hline 6 & & 300 & 17 & 19.5 & 3.1 & 135.2 & 119.1 & 78.5 \\
\hline
\end{tabular}

${ }^{a}$ Polymerization conditions: $100 \mathrm{~mL} n$-hexane, TEA co-catalyst, $0.5 \mathrm{~h}, 1 \mathrm{~atm}, 40{ }^{\circ} \mathrm{C}$.

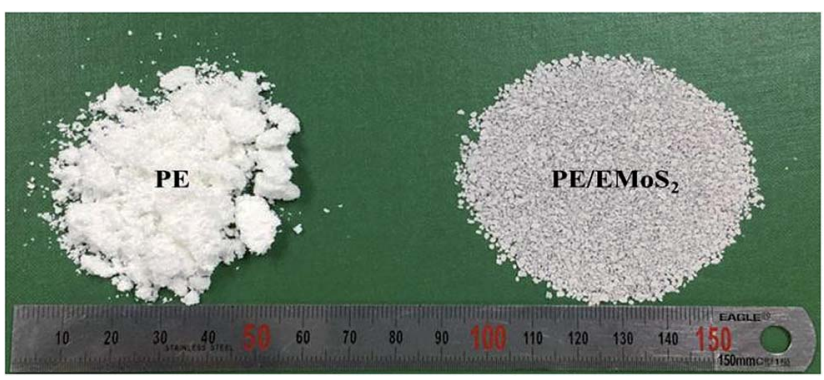

Fig. 3 Optical images of PE and PE/EMoS 2 nanocomposites.

The effects of the $\mathrm{EMoS}_{2}$ fillers on the melting temperature, degree of crystallinity of PE was characterized using DSC; the typical DSC curves are summarized in Fig. S2. $\dagger$ As shown in Table 1, the $T_{\mathrm{m}}$ of $\mathrm{PE}$ prepared by $\mathrm{MoS}_{2}$-free catalyst was $133.2{ }^{\circ} \mathrm{C}$. Upon the introduction of the $\mathrm{EMoS}_{2}$ fillers, the values of $T_{\mathrm{m}}$ and $X_{\mathrm{c}}$ of $\mathrm{PE}$ gradually increased with the $\mathrm{EMoS}_{2}$ amount. The increase in $T_{\mathrm{m}}$ may be due to the interaction between the $\mathrm{EMoS}_{2}$ and the PE matrix, which restricts the motion of the PE chain. ${ }^{17}$ As compared to the neat PE sample, the $T_{\mathrm{c}}$ also increased with the introduction of $\mathrm{MoS}_{2}$ fillers, which demonstrates that the $\mathrm{EMoS}_{2}$ fillers can act as nucleating agents to induce PE crystallization.

The thermal degradation of $\mathrm{PE}$ and the $\mathrm{PE} / \mathrm{EMoS}_{2}$ nanocomposites with different weight fractions of $\mathrm{EMoS}_{2}$ fillers were investigated by TGA under $\mathrm{N}_{2}$ atmosphere. The results are given in Table 2, and the TGA curves are shown in Fig. S3. $\dagger$ In comparison to the case of neat $\mathrm{PE}$, the thermal degradation temperatures are linearly shifted to the higher-temperature

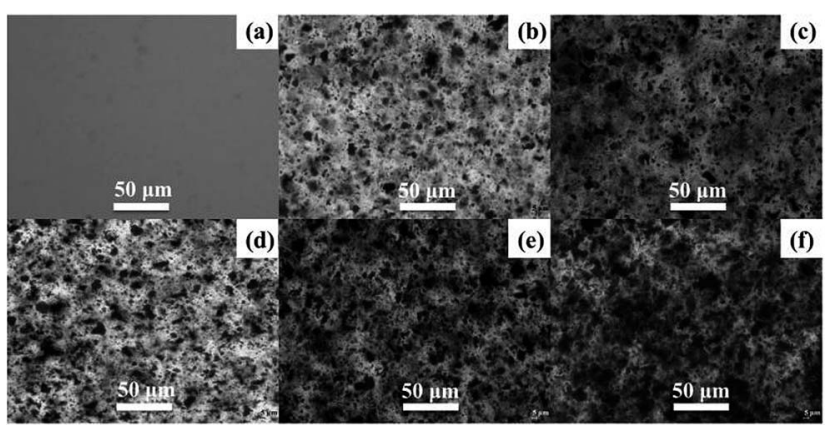

Fig. 4 Optical micrographs of (a) PE and PE/EMoS 2 nanocomposites with $\mathrm{EMOS}_{2}$ contents of (b) 0.4, (c) 0.7, (d) 0.9, (e) 2.0 and (f) 3.1 wt\%. region with the introduction of the $\mathrm{EMoS}_{2}$ fillers, indicating significant improvement in the thermal oxidation stability of PE. This enhancement of polymer thermal stability upon incorporation of the $\mathrm{EMoS}_{2}$ filler has already been reported by both ourselves and other groups. ${ }^{11-16}$ With the incorporation of $\mathrm{EMoS}_{2}$, the value of $T_{\mathrm{dmax}}$ of the $\mathrm{PE} / \mathrm{EMoS}_{2}$ nanocomposites increased to $\sim 486.5{ }^{\circ} \mathrm{C}$, which is $17.3{ }^{\circ} \mathrm{C}$ higher than that of the pure PE. The significant enhancement in the thermal stability of $\mathrm{PE}$ after the incorporation of $\mathrm{EMoS}_{2}$ could be ascribed to the good dispersion of $\mathrm{EMoS}_{2}$ in the PE matrix, which may act as an insulator between the heat source and the polymer surface where combustion occurs. In addition, the char yield of virgin $\mathrm{PE}$ is $0.9 \mathrm{wt} \%$ at $600{ }^{\circ} \mathrm{C}$, and those of all the $\mathrm{PE} / \mathrm{EMoS}_{2}$ nanocomposites are higher than that of the virgin PE. It is clear that the $\mathrm{EMoS}_{2}$ can catalyze the char formation of PE during the process of thermal degradation. These results are not unusual because the transition metal, molybdenum, can catalyze the char formation of polymers and sulfur can improve the flame retardancy of the polymers. ${ }^{\mathbf{1 4 , 1 8}}$ Considering the above results, it is believable that the introduction of inorganic components into organic polymers, such as $\mathrm{PE}$, can improve their thermal stabilities on the basis of the fact that $\mathrm{EMoS}_{2}$ fillers have good thermal stability due to the heat insulation effect of the $\mathrm{EMoS}_{2}$

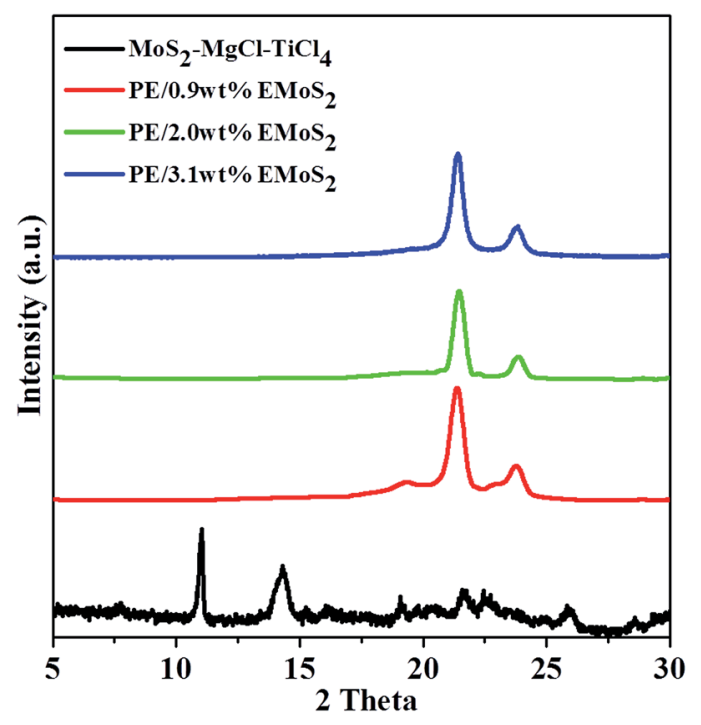

Fig. 5 XRD spectra of PE and PE/ODA-MoS 2 nanocomposites. 
Table 2 Effect of EMoS 2 content on the thermal stabilities of PE/ $\mathrm{EMoS}_{2}$ nanocomposites

\begin{tabular}{llll}
\hline $\begin{array}{l}\mathrm{EMoS}_{2} \text { content } \\
(\mathrm{wt} \%)\end{array}$ & $T_{\mathrm{d} 5 \%}\left({ }^{\circ} \mathrm{C}\right)$ & $T_{\mathrm{dmax}}\left({ }^{\circ} \mathrm{C}\right)$ & $\begin{array}{l}\text { Char yield } \\
(\mathrm{wt} \%)\end{array}$ \\
\hline- & 399.8 & 469.2 & 0.9 \\
0.9 & 430.9 & 485.3 & 4.8 \\
2.0 & 430.1 & 482.5 & 5.9 \\
3.1 & 431.8 & 486.5 & 7.8
\end{tabular}

Table 3 Mechanical properties of PE and PE/EMoS 2 nanocomposites with various $\mathrm{EMoS}_{2}$ contents

\begin{tabular}{lllll}
\hline & $\begin{array}{l}\mathrm{EMoS}_{2} \\
\text { content } \\
(\mathrm{wt} \%)\end{array}$ & $\begin{array}{l}\text { Tensile } \\
\text { strength } \\
(\mathrm{MPa})\end{array}$ & $\begin{array}{l}\text { Modulus } \\
(\mathrm{MPa})\end{array}$ & $\begin{array}{l}\text { Elongation } \\
\text { at break (\%) }\end{array}$ \\
\hline Neat PE & - & $25.6 \pm 1$ & $480 \pm 20$ & $1000 \pm 80$ \\
$\mathrm{PE} / \mathrm{EMOS}_{2}$ & 0.9 & $32.3 \pm 2$ & $720 \pm 30$ & $1600 \pm 90$ \\
nanocomposites & 2.0 & $35.4 \pm 2$ & $780 \pm 30$ & $1500 \pm 90$ \\
& 3.1 & $39.5 \pm 2$ & $1050 \pm 40$ & $1000 \pm 80$
\end{tabular}

layers and to the mass transport barrier to the volatile products generated during decomposition.

The mechanical properties of $\mathrm{PE}$ and the $\mathrm{PE} / \mathrm{EMoS}_{2}$ nanocomposites with various $\mathrm{EMoS}_{2}$ loadings were investigated by tensile tests and the results are presented in Table 3 . The values of the tensile strength, the modulus, and the elongation at break for the resultant PE nanocomposites are significantly enhanced even at very low $\mathrm{EMoS}_{2}$ nanofiller loadings. With increasing the $\mathrm{EMoS}_{2}$ loading, the tensile strength and modulus drastically improved. The elongation at break value was also increased with the introduction of relatively lower amount of $\mathrm{EMoS}_{2}$. The maximum increase in tensile strength, modulus, and elongation at break value is $54 \%, 119 \%$ and $60 \%$, respectively. $\mathrm{Hu}$ et $a l .{ }^{19}$ reported that the largest increase in tensile strength and modulus was 16.8 and $37.5 \%$ for $\mathrm{PE} / \mathrm{MoS}_{2}$ nanocomposites that prepared from solution mixing method, which is much lower than our results. These results indicate that the $\mathrm{PE} / \mathrm{EMoS}_{2}$ nanocomposites obtained by in situ polymerization with the $\mathrm{MoS}_{2}-\mathrm{MgCl}-\mathrm{TiCl}_{4}$ catalyst, exhibit remarkable combination of stiffness and toughness.

\section{Conclusions}

A new concept for ethylene polymerization using $\mathrm{MoS}_{2}-\mathrm{MgCl}-$ supported Ti-based Ziegler-Natta catalyst was successfully established by the intercalation of Ziegler-Natta catalyst into $\mathrm{MoS}_{2}$ galleries. After the in situ polymerization of ethylene, PE/ $\mathrm{EMoS}_{2}$ nanocomposites with well-dispersed $\mathrm{EMoS}_{2}$ nanofillers were fabricated. The resultant $\mathrm{PE} / \mathrm{EMoS}_{2}$ nanocomposites displayed enhanced thermal stability as compared to PE obtained from the $\mathrm{MoS}_{2}$-free catalyst system. The mechanical properties of PE were enhanced significantly even with a very small amount of the $\mathrm{EMoS}_{2}$ nanofiller. Thus, this work provides a facile approach for the production of high-performance PE with good thermal stability and excellent stiffness-toughness balance.

\section{Conflicts of interest}

There are no conflicts to declare.

\section{Acknowledgements}

This work was supported by the National Natural Science Foundation of China (No. U1462124) and National Research Foundation of Korea (NRF) grant (NRF-2015R1D1A1A0161012). The authors would also like to acknowledge the financial support from Key Scientific Research Project of Education Department (No. 2016-183) and Young Elite Scientist Sponsorship Program of Jilin Province.

\section{Notes and references}

1 H. Kim and C. W. Macosko, Macromolecules, 2008, 41, 3317.

2 Y. Huang, Y. Qin, Y. Zhou, H. Niu, Z. Z. Yu and J. Y. Dong, Chem. Mater., 2010, 22, 4096.

3 H. X. Zhang, M. G. Bae, J. H. Park, E. B. Ko, D. H. Lee, X. Q. Zhang and K. B. Yoon, RSC Adv., 2016, 6, 20734.

4 H. X. Zhang, Y. M. Hu, D. H. Lee, K. B. Yoon and X. Q. Zhang, RSC Adv., 2016, 6, 26553.

5 E. Benavente, M. A. S. Ana, F. Mendizábal and G. González, Coord. Chem. Rev., 2002, 224, 87.

6 P. Joensen, R. Frindt and S. R. Morrison, Mater. Res. Bull., 1986, 21, 457.

7 H. Li, J. Wu, Z. Yin and H. Zhang, Acc. Chem. Res., 2014, 47, 1067.

8 X. Fan, P. Xu, D. Zhou, Y. Sun, Y. C. Li, M. A. T. Nguyen, M. Terrones and T. E. Mallouk, Nano Lett., 2015, 15, 5956.

9 X. Li and H. Zhu, J. Materiomics, 2015, 1, 33.

10 Z. Tang, Q. Wei and B. Guo, Chem. Commun., 2014, 50, 3934. 11 K. Zhou, J. Liu, W. Zeng, Y. Hu and Z. Gui, Compos. Sci. Technol., 2015, 107, 120.

12 K. Zhou, W. Yang, G. Tang, B. Wang, S. Jiang, Y. Hu and Z. Gui, RSC Adv., 2013, 3, 25030.

13 K. Zhou, J. Liu, Q. Zhang, Y. Shi, S. Jiang, Y. Hu and Z. Gui, Mater. Lett., 2014, 126, 159.

14 K. Zhou, S. Jiang, C. Bao, L. Song, B. Wang, G. Tang, Y. Hu and Z. Gui, RSC Adv., 2012, 2, 11695.

15 H. X. Zhang, E. B. Ko, J. H. Park, Y. K. Moon, X. Q. Zhang and K. B. Yoon, Compos. Sci. Technol., 2016, 137, 9.

16 H. X. Zhang, E. B. Ko, J. H. Park, Y. K. Moon, X. Q. Zhang and K. B. Yoon, Composites, Part A, 2017, 93, 82.

17 L. Cui and S. I. Woo, Polym. Bull., 2008, 61, 453.

18 T. Tang, X. C. Chen, X. Y. Meng, H. Chen and Y. P. Ding, Angew. Chem., Int. Ed., 2005, 44, 1517.

19 X. Feng, P. Wen, Y. Cheng, L. Liu, Q. Tai, Y. Hu and K. M. Liew, Composites, Part A, 2016, 81, 61. 